\title{
Analisa Unjuk Kerja Software Defined Radio (SDR) dengan Teknik Quadrature Amplitude Modulation (QAM)
}

\author{
Jenny Putri Hapsari ${ }^{1^{*}}$, Munaf Ismail ${ }^{2}$ \\ ${ }^{1,2}$ Program Studi Teknik Elektro, Universitas Islam Sultan Agung \\ ${ }_{1,2}^{2} \mathrm{Jln}$. Raya Kaligawe Km 4, Semarang, 50112, Indonesia \\ E-mail: jenny@unissula.ac.id ${ }^{1}$, munaf@unissula.ac.id ${ }^{2}$
}

\section{Info Naskah:}

Naskah masuk: 28 Mei 2021

Direvisi: 16 Agustus 2021

Diterima: 20 Agustus 2021

\begin{abstract}
Abstrak
Perkembangan teknologi komunikasi nirkabel, menuntut adanya teknologi (software dan hardware) yang dapat mengikuti perubahan standar. Platform SDR (Software Defined Radio) merupakan teknologi nirkabel berbasis software yang dapat mengikuti perkembangan teknologi tanpa merubah hardware. WARP merupakan salah satu platform SDR yang dikembangkan oleh Universitas Rice Amerika. Penelitian ini bertujuan untuk mengetahui unjuk kerja SDR dengan teknik QAM. Unjuk kerja sistem ditunjukkan pada BER yang dihasilkan dengan menvariasikan jarak antara transmitter dan receiver dan level QAM. Penelitian dilakukan di dua lingkungan (indoor dan outdoor) dengan propagasi LOS. Hasil unjuk kerja menunjukkan bahwa nilai BER 4QAM di kedua lingkungan paling kecil jika dibandingkan level lainnya. Nilai BER 4QAM indoor adalah 0.0023 dan outdoor adalah 0 untuk jarak 6 meter, sehingga unjuk kerja 4-QAM outdoor lebih baik dibandingkan indoor. Unjuk kerja SDR dapat diperbaiki dengan menggunakan teknik QAM.
\end{abstract}

\section{Keywords:}

software defined radio;

QAM;

WARP;

BER.

\section{Abstract}

The development of wireless communication technology require technology (software and hardware) that can keep up with changing standards. SDR platform is a softwarebased wireless technology that can keep up with technological developments without changing hardware. WARP is one of SDR platforms developed by American Rice University. This research to determine the performance of the SDR with the QAM technique. The performance system can be seen from BER for different distance between transmitter and receiver and different level QAM. The research was carried in two enviroment (indoor and outdoor) with LOS propagation. The results show that the value of BER 4-QAM in the two enviroment is the smallest than another levels. The value of BER 4-QAM at indoor is 0.0023 and outdoors is 0 for a distance of 6 meters, so the performance of outdoor is better than indoor. SDR performance can be improved using QAM techniques. 


\section{Pendahuluan}

Perkembangan teknologi nirkabel sangatlah pesat, oleh sebab itu bidang komunikasi nirkabel sangatlah penting untuk dikembangkan. Perkembangan komunikasi data yang berupa video, gambar, suara melalui internet sejalan dengan perkembangan komunikasi bergerak. Pengguna menginginkan sebuah sistem komunikasi yang mempunyai kecepatan tinggi dengan QOS yang memadai serta mempunyai keamanan yang tinggi untuk komunikasi nirkabel. Sejalan dengan keinginan pengguna maka terjadi perubahan standar komunikasi sehingga timbul masalah kompatibilitas bagi penyedia jasa telekomunikasi. Hardware yang digunakan harus mengikuti perubahan standar komunikasi, sehingga perlu investasi hardware baru yang akan menyebabkan mahalnya biaya operasional. Software Defined Radio (SDR) merupakan teknologi nirkabel yang berbasis software, sehingga dengan adanya perubahan standar komunikasi tidak diperlukan perubahan hardware. SDR menggunakan pengolahan sinyal digital dimana hardware akan dikoneksikan ke bus kemudian mengunduh software. SDR dapat menyesuaikan software terbaru, sehingga dapat mengurangi waktu perkembangan produk [1][2]. Platform SDR berbiaya rendah, andal, serbaguna, fleksibel, dan open source serta mendukung pengembangan untuk eksperimen secara realtime. Perangkat SDR menggunakan spektrum RF dan mendigitalkan sinyal $\mathrm{I} / \mathrm{Q}$ yang dikirim dengan rentang spektrum frekuensi $25 \mathrm{MHz}$ hingga $1.75 \mathrm{GHz}$. Rentang spektrum yang sangat luas ini memungkinkan digunakan pada radio FM, sinyal ISM, radio seluler GSM, 3G, LTE, GPS, dan sebagainya.[3], [4], [5], [6], [7].

Salah satu platform SDR yang dikembangkan oleh Universitas Rice Amerika adalah Wireless Open Access Research Platform (WARP). WARP merupakan platform open-access yang scalable, extensible, dan secara real time mampu menerapkan algoritma di layer PHY dan MAC. WARP terdapat lima komponen yaitu hardware yang fleksibel, platform, paket yang mendukung, repositori yang dapat diakses secara terbuka, dan aplikasi untuk penelitian [8], [9], [10], [11].

Penelitan yang menggunakan WARP sudah dilakukan di berbagai bidang, yaitu penerapan BidMAC pada WARP[12], skema penambahan Partial Transmit Sequence (PTS)[13], metode energy saving Parctical Energy Detection (PED)[14], sistem SC-FDMA.[15], [16] Penelitian tentang sistem komunikasi multihop dengan WARP dilakukan di tahun 2016. Penelitian ini menggunakan modulasi PSK dan memberikan kesimpulan bahwa komunikasi multihop lebih baik dari komunikasi SISO berdasarkan nilai BER yang didapat dengan memvariasikan daya pancar [17].

Algoritma deteksi energi yang diterapkan menggunakan WARP dilakukan penelitian di tahun 2016. Penelitian ini menggunakan modulasi QPSK. Hasil SNR -4 $\mathrm{dBm}$ dan $-7 \mathrm{dBm}$, serta waktu deteksi $4 \mu \mathrm{s}$.[18] Penelitian WARP dalam komunikasi SISO yang dimanfaatkan untuk mendeteksi objek dan pengukuran RCS dilakukan 2015. Penelitian ini menggunakan modulasi M-PSK. Penelitian ini berguna untuk organisasi pertahanan dan dapat digunakan dalam kehidupan sehari-hari [19].
Tahun 2016 WARP telah digunakan untuk penerapan sisem komunasi kooperatif. Penelitian ini menggunakan modulasi QPSK dan dilakukan pada kondisi berpenghalang dan tanpa penghalang. Penelitian ini mengukur nilai BER dengan memvariasikan daya pancar.[20] WARP digunakan untuk mengevaluasi MC DS CDMA. Penelitian ini menggunakan modulasi QPSK dan mengukur BER dengan memvariasikan daya pancar untuk dua variasi jarak.[21] Teknik pemilihan relay dan skema network coding telah diterapkan pada modul WARP. Penelitian ini dilakukan di tahun 2021, dan mengukur throughput untuk mengetahui unjuk kerjanya [22].

Penelitian yang telah dilakukan menggunakan teknik modulasi PSK untuk penerapan WARP, dimana PSK hanya memperhatikan pergeseran phase. Sehingga nilai BER akan cukup tinggi untuk daya pancar yang tinggi. Pada penelitian ini, penerapan SDR dengan modul WARP menggunakan teknik QAM, dimana QAM ini memperhatikan pergeseran phase dan amplitudo. QAM memiliki keunggulan dapat meminimalisir ketidaksesuaian fase dan penundaan waktu, dapat menurunkan nilai BER, efisiensi daya dan bandwidth.[23], [24], [25] Teknik QAM sudah di terapkan pada komunikasi menggunakan media fiber optik dan komunikasi MIMO tetapi bukan pada platform SDR [26], [27].

Penelitian yang telah dilakukan masih menggunakan teknik modulasi PSK. Di sisi lain, teknik QAM mempunyai keunggulan dibandingkan dengan teknik PSK. Sehingga, pada penelitian ini akan menerapkan teknik QAM pada SDR. Peneltian ini bertujuan untuk mengetahui unjuk kerja SDR dengan menggunakan teknik QAM. Unjuk kerja SDR dilihat dari nilai BER dengan memvariasikan jarak antar antena yang dilakukan di dua lingkungan (indoor dan outdoor).

\section{Metode}

Penelitian ini dimulai dengan melakukan simulasi teknik QAM pada sistem komunikasi SISO menggunakan kanal ideal. Simulasi menggunakan Matlab dan banyaknya bit yang dikirimkan adalah $10^{3}$ bit. Analisa unjuk kerja teknik QAM didapatkan dari nilai Bit Error Rate (BER) dengan variasi nilai Energy per Bit to the Spectral Noise Density (Eb/No). Design simulasi ditunjukkan Gambar 1.

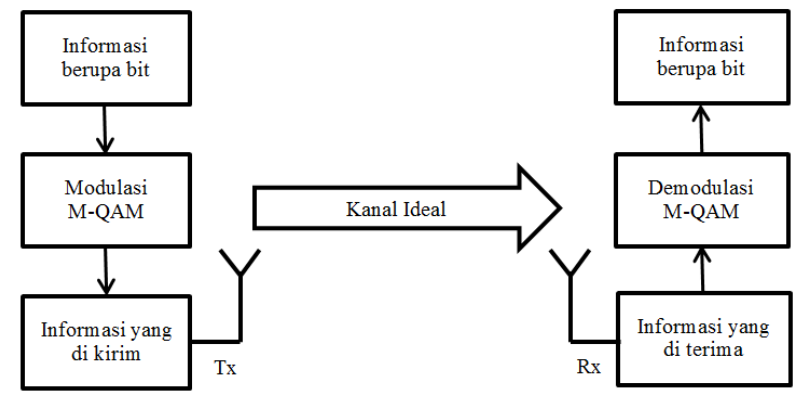

Gambar 1. Desain Simulasi Teknik QAM Pada Sistem SISO

Tahap selanjutnya dilakukan penerapan teknik QAM sistem komunikasi SISO di WARP. Adapun parameter yang disetting di modul WARP ditunjukkan pada Tabel 1. 
Design penerapan teknik QAM ke WARP ditunjukkan Gambar 2.

Tabel 1. Parameter setting WARP

\begin{tabular}{clc}
\hline No & \multicolumn{1}{c}{ Parameter } & Nilai \\
\hline 1 & Jumlah bit & 30000 \\
2 & delay & 200 \\
3 & Kanal Carrier & 12 \\
4 & $T x \_B B$ & 1 \\
5 & $T x \_R f$ & 30 \\
6 & $T x \_R f(d B m)$ & $-25.16 \mathrm{dBm}$ \\
7 & $R x \_B B$ & 10 \\
8 & $R x \_R f$ & 1 \\
\hline
\end{tabular}

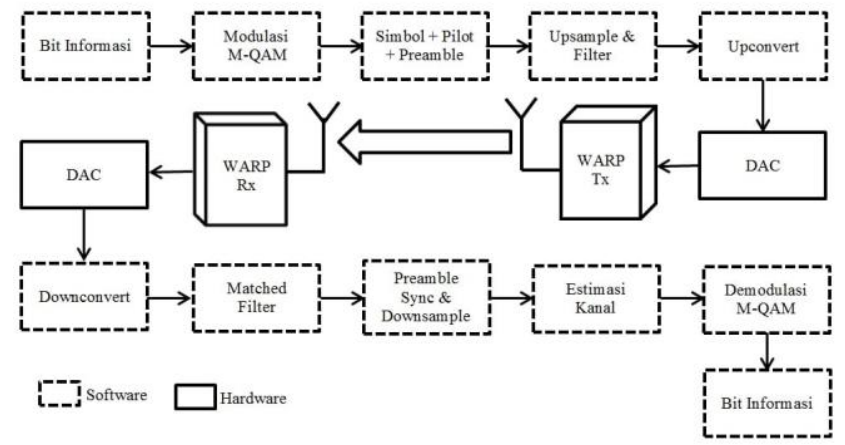

Gambar 2. Desain Teknik QAM di Modul WARP

Tahap penerapan ada yang dilakukan dengan software yaitu Matlab dan hardware yaitu modul WARP. Tahap yang dilakukan menggunakan software adalah pembangkitan bit sebagai informasi, teknik QAM, penambahan pilot dan preamble, up-sampling, filter, upconverter di sisi pengirim, dan down-converter, match filter, down-sampling, deteksi preamble dan estimasi kanal, demodulasi di sisi penerima. Hardware modul WARP sendiri digunakan untuk pengirim dan penerima dimana dipasang masing-masing satu antena yang terletak $40 \mathrm{~cm}$ di atas lantai. Pada hardware WARP dilakukan proses normalisasi yang bertujuan untuk mengoptimalkan DAC di sisi pengirim dan ADC di sisi penerima.

Pembangkitan bit sebagai informasi yang dikirim berupa bit acak biner. Bit tersebut kemudian dilakukan pembetukan simbol sesuai dengan level QAM. Simbol yang dihasilkan digunakan sebagai input pada proses modulasi. Hasil modulasi, setiap simbol akan menjadi simbol kompleks. Proses selanjutnya adalah menambahkan deretan simbol tersebut dengan pilot, bertujuan untuk proses mengestimasi kanal. Tipe estimasi kanal yang digunakan adalah flat fading dan jumlah tap yaitu satu.

Tahap selanjutnya adalah penambahan deretan preamble, yang bertujuan untuk mendeteksi letak awal simbol informasi yang diterima. Jumlah simbol preamble adalah 13 simbol. Korelasi antara preamble dan informasi yang diterima digunakan untuk proses pendeteksian. Sampling rate ditingkatkan dengan menggunakan upsample, dimana menggunakan nilai 8 untuk over sampling rate. Match filter di sisi penerima digunakan untuk menghilangkan frekuensi tinggi. Pelemahan DC dihindari dengan menggunakan proses upconvert di sisi pengirim dan downconvert di sisi penerima.
Penelitian ini dilakukan di dua lingkungan dengan propagasi LOS untuk mendapatkan nilai BER. Penelitian ini dilakukan dengan memvariasikan jarak antar antena. Pada lingkungan indoor, jarak dimulai dari 1 meter sampai 6 meter dengan interval 1 meter. Jarak maksimal di lingkungan indoor adalah 6 meter dikarenakan keterbatasan ruangan yang dapat digunakan untuk LOS. Pada lingkungan outdoor, jarak dimulai dari 1 meter sampai 10 meter dengan interval 1 meter. Skema pengukuran dapat dilihat pada Gambar 3.

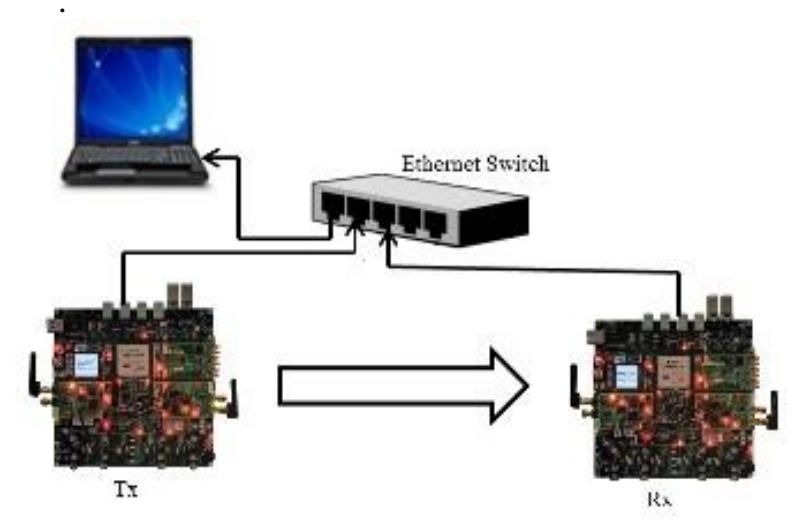

Gambar 3. Skema konfigurasi modul WARP

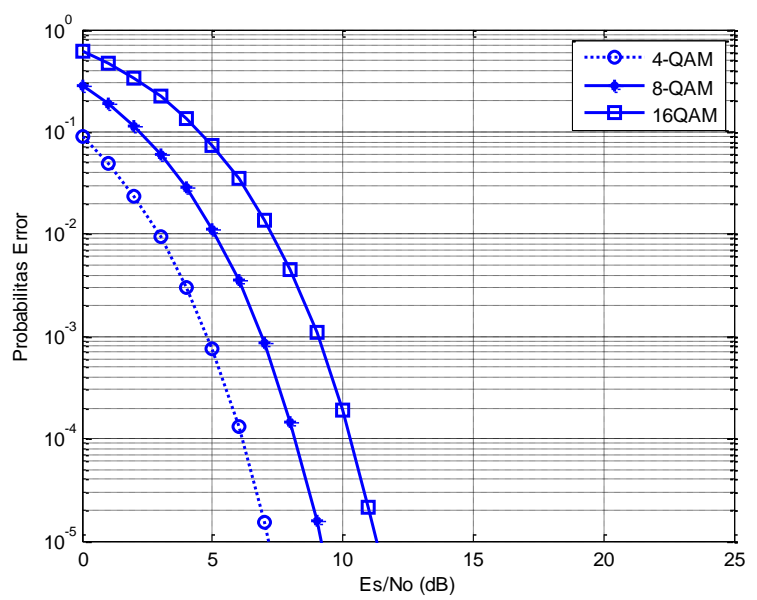

Gambar 4. Eb/No Vs BER hasil simulasi

\section{Hasil dan Pembahasan}

Penelitian ini menguraikan hasil simulasi dan hasil penerapan secara realtime platform Software Defined Radio (SDR) di modul WARP dengan teknik QAM untuk sistem komunikasi SISO. Nilai M-Aray/ level modulasi yang diterapkan pada QAM adalah 4, 8, dan 16. Gambar 4 menunjukkan hasil simulasi unjuk kerja modulasi QAM untuk level 4, 8, dan 16. Simulasi yang dilakukan merupakan fungsi $\mathrm{Eb} / \mathrm{No}$ terhadap BER .

Nilai BER untuk masing-masing level secara berurutan adalah $7.5 \times 10^{-4}, 1.12 \times 10^{-2}$, dan $7.2 \times 10^{-2}$; untuk Eb/No 5 dB. Pada Gambar 4 tersebut juga memperlihatkan bahwa teknik QAM dengan level 4 mempunyai nilai BER yang paling baik dibandingkan dengan level 8 dan 16 untuk semua nilai Eb/No. Hasil penerapan secara realtime platform Software Defined Radio 
(SDR) di modul WARP dengan teknik QAM untuk sistem komunikasi SISO di indoor diperlihatkan Gambar 5.

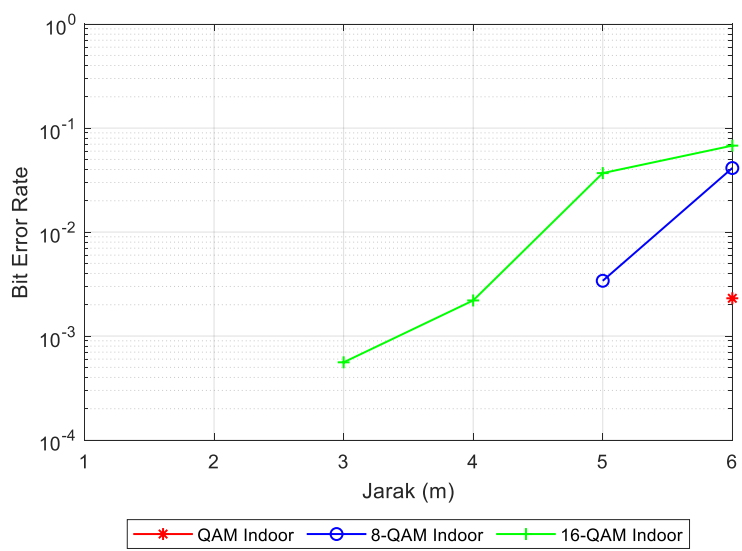

Gambar 5. Hasil unjuk kerja dari QAM, 8-QAM, dan 16-QAM di indoor

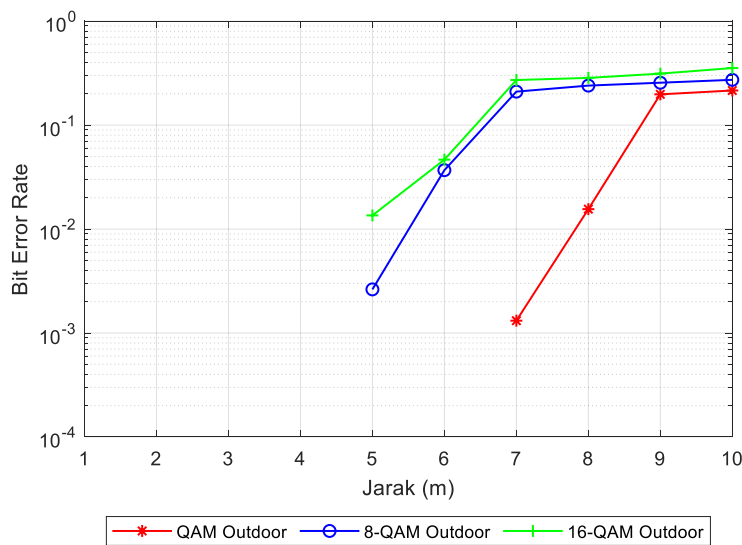

Gambar 6. Hasil unjuk kerja dari QAM, 8-QAM, dan 16-QAM di outdoor

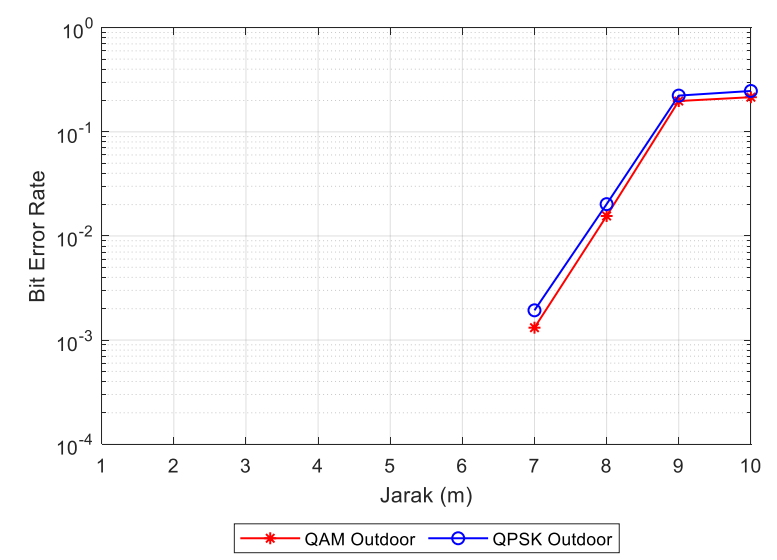

Gambar 7. Hasil unjuk kerja dari QAM dan QPSK di outdoor

Teknik modulasi 4-QAM/QAM memiliki hasil BER yang paling baik dibandingkan 8-QAM dan 16-QAM untuk semua variasi jarak, terlihat pada Gambar 5. Pada jarak 1 dan 2 meter, nilai BER masih 0 untuk semua level, karena jarak antar node yang dekat sehingga noise yang ada relatif kecil dan tidak mempengaruhi sinyal yang dikirimkan. Pada jarak 3 meter dan seterusnya terjadi perubahan nilai BER yang cukup signifikan untuk semua level, hal ini disebabkan besarnya noise yang terdapat pada kedua jarak tersebut, serta euclidean distance untuk setiap level. Hubungan jarak dan noise berbanding lurus, dimana jika jarak semakin panjang maka noise semakin besar. Sedangkan, euclidean distance untuk level 16 lebih kecil dibandingkan level 8 dan 4, sehingga banyak bit error pada level 16 lebih banyak dibandingkan dengan level 8 dan 4 . Hubungan antara euclidean distance dan jumlah bit error berbanding terbalik. Gambar 6 menunjukkan hasil penerapan di lingkungan outdoor.

Pada Gambar 6, level 4 juga memiliki unjuk kerja yang paling baik di lingkungan outdoor. Nilai BER untuk jarak 1 meter sampai 4 meter masih 0, sedangkan mengalami kenaikan yang signifikan di jarak 5 meter dan seterusnya untuk level 8 dan 16. Level 4 mulai mengalami kenaikan pada jarak 7 meter dan seterusnya. Perubahan nilai BER diakibatkan banyaknya noise untuk setiap jarak dan euclidean distance untuk setiap level.

Pada penerapan yang dilakukan di lingkungan indoor dan outdoor didapatkan unjuk kerja QAM dengan level 4 paling baik. Hasil BER level 4 untuk outdoor lebih baik daripada di indoor, hal ini dapat dilihat dari nilai BER level 4 saat jarak 6 meter. BER dari dari level 4 untuk indoor adalah 0.002 dan outdoor adalah 0. Pada gambar 5 dan 6 terlihat bahwa kelandaian grafik berbeda dengan simulasi, hal ini karena saat penerapan terjadi kondisi multipath.

Pada Gambar 7 menunjukkan perbandingan unjuk kerja 4-QAM dan QPSK/4-PSK yang merupakan hasil dari penelitian sebelumnya.[28] Pada gambar 7 menunjukkan bahwa QAM memiliki unjuk kerja yang lebih baik dibandingkan QPSK. BER QAM adalah 0.001314 dan QPSK adalah 0.00193 untuk jarak 7 meter. Pada jarak yang lain, nilai BER QAM selalu lebih kecil dibandingkan QPSK

\section{Kesimpulan}

Hasil penerapan platform Software Defined Radio (SDR) di modul WARP dengan teknik QAM secara realtime untuk sistem komunikasi SISO menujukkan bahwa level 4 mempunyai unjuk kerja yang paling baik di kedua lingkungan. Nilai BER QAM level 4 lebih kecil dibandingkan level 8 dan 16. Unjuk kerja teknik QAM lebih baik dibandingkan dengan teknik PSK untuk sistem komunikasi SISO, hal ini ditunjukkan dengan melihat nilai BER untuk kedua teknik. Sehingga dengan menggunakan teknik QAM dapat memperbaiki unjuk kerja platform SDR. Penelitian ini dapat dikembangkan dengan menerapkan teknik QAM pada modul SDR lainnya dan menggunakan sistem komunikasi yang lebih kompleks misal sistem komunikasi MIMO ataupun kooperatif.

\section{Daftar Pustaka}

[1] B. Li, "Analysis and Design of Software Defined Radio," Int. Conf. Internet Comput. Inf. Serv., pp. 415-418, 2011.

[2] E. Grayver, Implementing Software Defined Radio. 2013.

[3] A. Carolina et al., "Why Software-Defined Radio ( SDR ) Matters in Healthcare?," Med. Technol. J., vol. 3, no. 
September, pp. 421-429, 2019.

[4] A. M. Wyglinski, D. P. Orofino, M. N. Ettus, and T. W. Rondeau, "Revolutionizing software defined radio: case studies in hardware, software, and education," IEEE Commun. Mag., vol. 54, no. 1, pp. 68-75, 2016.

[5] R. W. Stewart et al., "A low-cost desktop software defined radio design environment using MATLAB, simulink, and the RTL-SDR," IEEE Commun. Mag., vol. 53, no. 9, 2015.

[6] R. Krishnan, R. G. Babu, S. Kaviya, N. P. Kumar, C. Rahul, and S. S. Raman, "Software defined radio (SDR) foundations, technology tradeoffs: A survey," in 2017 IEEE International Conference on Power, Control, Signals and Instrumentation Engineering (ICPCSI), 2017, pp. 2677 2682.

[7] D. Sinha, A. K. Verma, and S. Kumar, "Software defined radio: Operation, challenges and possible solutions," 10th Int. Conf. Intell. Syst. Control, 2016.

[8] "warp." [Online]. Available: http://warp.rice.edu/trac/. [Accessed: 20-Apr-2021].

[9] P. Murphy, A. Sabharwal, and B. Aazhang, "Design of WARP: A wireless open-access research platform," Eur. Signal Process. Conf., no. Eusipco, 2006.

[10] L. Li, M. Beach, R. Nejabati, and D. Simeonidou, "Building SDN Agent for Wireless Local Area Networks," IEEE Wirel. Commun. Netw. Conf., 2019.

[11] O. Holland, H. Bogucka, and A. Medeisis, Opportunistic spectrum sharing and white space access: The practical reality. John Wiley \& Sons, 2015.

[12] R. Palacios, F. Franch, F. Vazquez-Gallego, J. AlonsoZarate, and F. Granelli, "Experimental evaluation of reverse direction transmissions in WLAN using the WARP platform," in 2015 IEEE International Conference on Communications (ICC), 2015, pp. 6139-6145.

[13] S. W. Yoga, T. Suryani, and Suwadi, "Application PTS technique for PAPR reduction in MIMO OFDM using WARP," Int. Semin. Intell. Technol. Its Appl., 2016.

[14] T. Manna and I. S. Misra, "Design of Resource/EnergyEfficient Energy Detector for Real-Time Cognitive Radio using WARP," Int. Conf. Opto-Electronics Appl. Opt., 2019.

[15] K. S. Ramtej and S. Anuradha, "Experimental Validation of Improved Exponential Companding Technique for SCFDMA Systems Using WARP Hardware," J. Circuits, Syst. Comput., vol. 29, no. 10, p. 2050154, 2020.

[16] S. R. Kondamuri and S. Anuradha, "Walsh-Hadamardtransform-based SC-FDMA system using WARP hardware," ETRI J. Wiley, 2021.

[17] I. Anisah and H. Briantoro, "Implementation of relay demodulate and forward on multihop communication system using wireless open access research platform (WARP) module," Int. Electron. Symp., 2016.

[18] H. Yerranna, S. L. Sabat, D. K. Sunil, and S. K. Udgata, "Real time performance evaluation of energy detection based spectrum sensing algorithm using WARP board," Int. Conf. Adv. Comput. Commun. Informatics, 2016.

[19] S. Shome, R. Bera, B. Maji, S. N. Sur, and S. Bera, "Embedded Digital SISO Radar using Wireless Open Access Research Platform for Object Detection and RCS Measurement," I.J. Image, Graph. Signal Process., vol. 12, no. November, pp. 47-53, 2015.

[20] G. E. W. Pratama, Suwadi, and T. Suryani, "Implementasi Sistem Komunikasi Kooperatif OFDM pada Wireless Open Access Research Plaform," Semin. Nas. Inov. dan Apl. Teknol. di Ind., pp. 173-178, 2016.

[21] Suwadi, T. Suryani, D. Kuswidiastuti, V. Hariadi, and D. A. Gunastut, "Performance Evaluation of MC DS CDMA using Wireless Open Access Research Platform," J. Adv. Res. Electr. Eng., vol. 2, no. 2, pp. 49-54, 2018.

[22] N. Hidayati, R. A. Wijayanti, A. W. Yulianto, and D. Marya, "Skema network coding dan teknik pemilihan relay pada modul WARP di lingkungan indoor," J. ELTEK, vol. 19, no. 1, pp. 43-51, 2021.

[23] M. S. Faruk and K. Kikuchi, "Compensation for In-Phase / Quadrature Imbalance in Coherent-Receiver Front End for Optical Quadrature Amplitude Modulation Compensation for In-Phase / Quadrature Imbalance in Coherent-Receiver Front End for Optical Quadrature," IEEE Photonics J., vol. 5, no. 2, p. 7800110, 2013.

[24] D. Yoon, K. Cho, and J. Lee, "Bit error probability of M-ary quadrature amplitude modulation," Veh. Technol. Conf. Fall 2000. IEEE VTS Fall VTC2000. 52nd Veh. Technol. Conf. (Cat. No.00CH37152), 2000.

[25] X. Li, "Simulink-based Simulation of Quadrature Amplitude Modulation ( QAM ) System," Proc. 2008 IAJC-IJME Int. Conf., vol. 11, 2008.

[26] T. Fehenberger, A. Alvarado, G. Böcherer, and N. Hanik, "On Probabilistic Shaping of Quadrature Amplitude Modulation for the Nonlinear Fiber Channel," J. Light. Technol., vol. 34, pp. 5063-5073, 2016.

[27] P. Shaik, P. K. Singya, and V. Bhatia, "Performance analysis of QAM schemes for non-regenerative cooperative MIMO network with transmit antenna selection," $A E U$ International J. Electron. Commun., vol. 107, pp. 298-306, 2019.

[28] J. P. Hapsari, "Implementasi Sistem Komunikasi SingleInput Single-Outpt Pada Lingkungan Indoor Dan Outdoor Menggunakan Teknik Modulasi PSK Berbasis WARP," Media Elektr., vol. 9, no. 1, pp. 6-24, 2016. 